\title{
Synthesis and thermal expansion hysteresis of $\mathrm{Ca}_{1-x} \mathrm{Sr}_{x} \mathrm{Zr}_{4} \mathbf{P}_{6} \mathbf{O}_{24}$
}

\author{
BASAVARAJ ANGADI, V M JALI*, M T LAgARE, N S KINI ${ }^{\dagger}$ and A M UMARJI \\ Department of Physics, Gulbarga University, Gulbarga 585 106, India \\ ${ }^{\dagger}$ Materials Research Centre, Indian Institute of Science, Bangalore 560 012, India
}

MS received 17 January 2000; revised 26 March 2002

\begin{abstract}
The low thermal expansion ceramic system, $\mathrm{Ca}_{1-x} \mathrm{Sr}_{x} \mathrm{Zr}_{4} \mathbf{P}_{6} \mathrm{O}_{24}$, for the compositions with $x=0$, $0 \cdot 25,0 \cdot 50,0.75$ and 1 was synthesized by solid-state reaction. The sintering characteristics were ascertained by bulk density measurements. The fracture surface microstructure examined by scanning electron microscopy showed the average grain size of $2.47 \mu \mathrm{m}$ for all the compositions. The thermal expansion data for these ceramic systems over the temperature range $25-800^{\circ} \mathrm{C}$ is reported. The sinterability of various solid solutions and the hysteresis in dilatometric behaviour are shown to be related to the crystallographic thermal expansion anisotropy. A steady increase in the amount of porosity and critical grain size with increase in $x$ is suggested to explain the observed decrease in the hysteresis.
\end{abstract}

Keywords. Low-thermal expansion; thermal expansion hysteresis; NZP ceramics.

\section{Introduction}

$\mathrm{Ca}_{1-x} \mathrm{Sr}_{x} \mathrm{Zr}_{4} \mathrm{P}_{6} \mathrm{O}_{24}$ (CSZP) system belongs to a large structural family of new low thermal expansion materials known as sodium zirconium phosphate (NZP) or calcium titanium phosphate (CTP) family discovered by Roy and co-workers (Alamo and Roy 1984; Roy et al 1984; Agrawal and Stubican 1985). The members of this family have received much attention in recent times because of their very low coefficient of thermal expansion (Alamo and Roy 1984; Lenain et al 1984; Roy et al 1984), controlled lattice thermal expansion anisotropy (Oota and Yamai 1986; Limaye et al 1987), fast ionic conductivity (Goodenough et al 1976; Hong 1976), high thermal and chemical stability (Harshe et al 1994) and flexibility towards ionic substitutions (Alamo and Roy 1986).

The NZP materials have an extraordinary crystal structure, which consists of a strongly bonded but flexible three-dimensional network of $\mathrm{PO}_{4}$ tetrahedra and $\mathrm{ZrO}_{6}$ octahedra. These polyhedra are interconnected through corner sharing, and develop a rigid and highly stable hexagonal lattice with structural holes that are partially or fully, depending upon the composition, occupied by calcium, strontium, sodium or any other substituting ion(s). The low thermal expansion behaviour of these materials is due to (i) strongly bonded polyhedra, (ii) the presence of structural holes which may absorb some of the thermal vibrations and (iii) anisotropy in the axial thermal expansions of the lattice. Lenain et al (1987) developed a structural model for thermal expansion based

*Author for correspondence on the rotation of polyhedral network and the coupling between octahedra and tetrahedra that successfully explained the thermal expansion behaviour of alkali analogues of NZP members.

The tailorability of the thermal expansion of NZP materials by carefully selecting the composition provides scope for the synthesis of near zero expansion materials over any desired temperature range. Limaye et al (1987) investigated the synthesis and thermal expansion of $\mathrm{MZr}_{4} \mathrm{P}_{6} \mathrm{O}_{24}(\mathrm{M}=\mathrm{Mg}, \mathrm{Ca}, \mathrm{Sr}, \mathrm{Ba})$ and found that $\mathrm{CaZr}_{4} \mathrm{P}_{6} \mathrm{O}_{24}(\mathrm{CZP})$ and $\mathrm{SrZr}_{4} \mathrm{P}_{6} \mathrm{O}_{24}(\mathrm{SZP})$ exhibited opposing anisotropy: with increase in temperature the $a$-axis contracts in CZP but expands in SZP; on the other hand, the $c$-axis expands in CZP but contracts in SZP. Often there have been disagreements between the values of thermal expansion coefficient, $\alpha$, derived from X-ray data and from dilatometric measurements. The difference can be attributed to the fact that in X-ray measurements with powder samples, particles are free to expand or contract while in dilatometric measurements on ceramics the particles are constrained. Ceramic bodies made out of such anisotropically expanding materials undergo extensive micro cracking during cooling from the sintered state and, hence, show characteristic hysteresis in bulk thermal expansion behaviour. The micro cracking due to thermal strain during cooling has been established through detection of acoustic emission during cooling cycles (Srikanth et al 1991). High sinter density and good mechanical strength are desired characteristics for enhancing the utility of these ceramics. Efforts have been made to improve mechanical strength and sinter density. Use of grain growth inhibitors such as in $\mathrm{Zr}_{2} \mathrm{P}_{2} \mathrm{O}_{9}$ (Yamai and Ota 1985), and of fine particles as in pseudobrookite 
family (Cleaveland and Bradt 1978) or altering the axial thermal expansion coefficients by proper ionic substitution have helped in overcoming the problem to some extent.

The micro cracking starts when the grain size exceeds critical grain size, which is related to the maximum thermal expansion difference as follows:

$$
G_{\mathrm{cr}}=\frac{k_{\text {,f }}}{E\left(\Delta \alpha_{\max }\right)^{2}(\Delta T)^{2}},
$$

where $G_{\mathrm{cr}}$ is the critical grain size of fracture, $k$ is a function of the geometry of the modelled grain, $\gamma_{f}$ the fracture surface energy, $E$ the Young's modulus, $\Delta \alpha=\left|\alpha_{a}-\alpha_{c}\right|$ is the anisotropic thermal expansion difference $\left(\alpha_{a}\right.$ and $\alpha_{c}$ being thermal expansion coefficients along the $a$ - and the $c$-axis respectively) and $\Delta \alpha_{\max }$ the maximum value of $\Delta \alpha$ for the hexagonal system over the temperature range $\Delta T$. If $\Delta \alpha_{\max }$ is high then $G_{\mathrm{cr}}$ will be small, which means that grain size has to be maintained below this value to achieve reasonable strength for the sintered ceramic. For example, in CSZP system it was found that the $x=0.50$ composition exhibited almost no anisotropy in its axial thermal expansion (Limaye et al 1991) and is therefore expected to be free from micro cracking. Indeed while cooling this material from $600^{\circ} \mathrm{C}$ no acoustic emission was detected for this composition whereas for $x=0$ and $x=1$ compositions considerable acoustic emission was detected (Srikanth et al 1991). This indicates dependence of thermal expansion anisotropy on composition and its manifestation in the form of micro cracking. To make a systematic investigation of the linkage between the density, thermal expansion anisotropy, micro cracking and thermal hysteresis, in the present work, five different compositions in CSZP were prepared and characterized over wider temperature range from $25-800^{\circ} \mathrm{C}$. The densification, lattice parameters, thermal expansion coefficient and hysteresis in dilatometric thermal expansion behaviour for all the compositions prepared under same processing conditions have been reported.

\section{Experimental}

\subsection{Synthesis}

In the system CSZP five compositions with $x=0,0 \cdot 25$, $0.50,0.75$ and 1 were synthesized by solid-state reaction method. Reagent grade $\mathrm{CaCO}_{3}, \mathrm{SrCO}_{3}, \mathrm{ZrO}_{2}$ and $\mathrm{NH}_{4} \mathrm{H}_{2} \mathrm{PO}_{4}$ were used as starting materials. The stoichiometric amounts of the desired composition were mixed and ground in acetone to homogenize and then airdried. The dry powder was calcined at different temperatures in steps to drive off the volatiles. The first step at $200^{\circ} \mathrm{C}$ for $15 \mathrm{~h}$ drove off water and $\mathrm{NH}_{3}$ and the second step at $600^{\circ} \mathrm{C}$ for $4 \mathrm{~h}$ produced a molten mass. On cooling, the mass was taken out of the furnace, ground again and subjected to the third step at $1000^{\circ} \mathrm{C}$ for $24 \mathrm{~h}$. The calcined product was crushed and $1 \mathrm{wt} \%$ of polyvinyl alcohol in aqueous medium was added to it as a binder. It was then cold pressed at a pressure of $50 \mathrm{kN}$ to get pellets of $12 \mathrm{~mm}$ diameter and $1 \mathrm{~cm}$ thickness. The pellets were finally sintered at $1250^{\circ} \mathrm{C}$ for $24 \mathrm{~h}$ to obtain the samples in single phase. The samples for each composition were characterized for their phase formation, density, microstructure and thermal expansion.

\section{$2.2 X R D$}

The phase identification for each of the sample was carried out by room temperature powder X-ray diffractometry (XRD) using Scintag X-ray diffractometer and $\mathrm{CuK}_{\alpha}(1.5406 \AA)$ radiation at a scan speed of $2^{\circ} / \mathrm{min}$ in the $2 \theta$ range $10^{\circ}$ to $70^{\circ}$. The theoretical XRD pattern was generated by the computer code Lazy Pulverix (Yvon et al 1977) and the lattice parameter refinement was done by the linear least squares method.

\subsection{Density}

The theoretical density was calculated using the lattice parameters obtained from XRD. The actual density was measured by the method based on the Archimedes principle, using distilled water as a displacement liquid and a Mettler electronic balance with the model AE 240 density measurement kit. A sample was first dried in oven at $120^{\circ} \mathrm{C}$ and then weighed to get dry weight $(D)$. Next, the sample was boiled in distilled water for $2 \mathrm{~h}$ and soaked for $24 \mathrm{~h}$. Then it was suspended in water and suspended weight $(S)$ was obtained. Finally, the sample was wiped with wet cloth to remove any water above the surface and weighed to get the wet weight $(W)$. Bulk density, true density and apparent porosity were calculated as follows:

$$
\begin{aligned}
& \text { Bulk density }=D /(W-S) \\
& \text { True density }=D /(D-S) \\
& \text { Apparent porosity }=[(W-D) /(W-S)] \times 100 \%
\end{aligned}
$$

\section{$2.4 \quad S E M$}

The microstructure of the fracture surface of a sample was obtained using Leica Cambridge Stereoscan model S-360 scanning electron microscope (SEM). The average grain size was determined from such pictures by the linear intercept technique (Wurst and Nelson 1972). Several test lines were drawn on a photograph and the number of intercepts between the test lines and grain boundaries were counted. The average grain size was obtained using the relation 
Table 1. The lattice parameters and the average thermal expansion coefficients for different compositions, $x$.

\begin{tabular}{|c|c|c|c|c|c|c|c|}
\hline \multirow{4}{*}{$\begin{array}{l}\text { Compo- } \\
\text { sition } \\
(x)\end{array}$} & & & \multicolumn{5}{|c|}{ Average thermal expansion coefficient } \\
\hline & & & \multicolumn{3}{|c|}{$\begin{array}{l}\text { From dilatometric measurements } \\
\qquad \alpha \times 10^{6}\left({ }^{\circ} \mathrm{C}^{-1}\right)\end{array}$} & \multicolumn{2}{|c|}{$\begin{array}{l}\text { From high temperature XRD } \\
\qquad \alpha_{1} \times 10^{6}\left({ }^{\circ} \mathrm{C}^{-1}\right)\end{array}$} \\
\hline & \multicolumn{2}{|c|}{$\begin{array}{l}\text { Lattice parameters } \\
\text { at } 25^{\circ} \mathrm{C}\end{array}$} & Present & Present & $\begin{array}{l}\text { Limaye } \\
\text { et al }\end{array}$ & $\begin{array}{l}\text { Calculated using } \\
\text { data from Limaye }\end{array}$ & $\begin{array}{l}\text { Calculated using } \\
\text { data from }\end{array}$ \\
\hline & $a(\AA)$ & $c(\AA)$ & $25-800^{\circ} \mathrm{C}$ & $25-500^{\circ} \mathrm{C}$ & $25-500^{\circ} \mathrm{C}$ & $25-500^{\circ} \mathrm{C}$ & $25-800^{\circ} \mathrm{C}$ \\
\hline 0 & $8 \cdot 785(5)$ & $22.693(14)$ & $-0.9(1)$ & $-1.4(1)$ & $-2 \cdot 11$ & $-0 \cdot 11$ & 1.67 \\
\hline $0 \cdot 25$ & $8 \cdot 758(5)$ & $22.920(14)$ & $0 \cdot 8(1)$ & $0 \cdot 1(1)$ & $0 \cdot 60$ & - & - \\
\hline $0 \cdot 50$ & $8 \cdot 729(4)$ & $23 \cdot 119(13)$ & $2 \cdot 1(1)$ & $1 \cdot 6(1)$ & 1.40 & $-0 \cdot 10$ & - \\
\hline $0 \cdot 75$ & $8 \cdot 720(4)$ & $23 \cdot 232(14)$ & $2 \cdot 3(1)$ & $2 \cdot 3(1)$ & $2 \cdot 50$ & - & - \\
\hline 1 & $8 \cdot 701(5)$ & $23 \cdot 390(13)$ & $2 \cdot 6(1)$ & $2 \cdot 6(1)$ & $3 \cdot 20$ & $2 \cdot 01$ & $2 \cdot 35$ \\
\hline
\end{tabular}

$$
D=1.56 C /(M N)
$$

where $D$ is the average grain size, $C$ the total length of test lines used, $N$ the number of intercepts, and $M$ the magnification of the photograph. The proportionality constant 1.56 is a correction factor which was derived by Mendelson for random slices through a model system consisting of space filling tetrakaidecahedrally shaped grains with a log-normal size distribution (Mendelson 1969).

\subsection{Thermal expansion}

The bulk thermal expansion measurements were made using a home-built high temperature dilatometer (Umarji et al 1997). The change in the length of the sample, kept in a quartz cell, was detected using a linear variable differential transformer (LVDT) that was maintained at $73^{\circ} \mathrm{C}$ to avoid the effect of ambient temperature on its performance. Sample temperature was varied from $25^{\circ} \mathrm{C}$ to $800^{\circ} \mathrm{C}$ at the rate of $2^{\circ} \mathrm{C} / \mathrm{min}$ during the heating and cooling cycles. The apparatus, calibrated using quartz and OFH copper, has a sensitivity of $0 \cdot 1 \times 10^{-6} /{ }^{\circ} \mathrm{C}$ for the measurement of $\alpha$. A PC based data acquisition system recorded thermal expansion data at intervals of $120 \mathrm{~s}$ averaged over $10 \mathrm{~s}$ at each point.

\section{Results and discussion}

\subsection{Phase}

The phase of the CZP $(x=0)$ and SZP $(x=1)$ samples were confirmed by comparing their XRD patterns with the standard JCPDS patterns No.33-321 and No.33-1360, respectively. All the five compositions in the CSZP system could be indexed on a hexagonal lattice and the lattice parameters calculated by the least squares method are shown in columns 2 and 3 of table 1 .

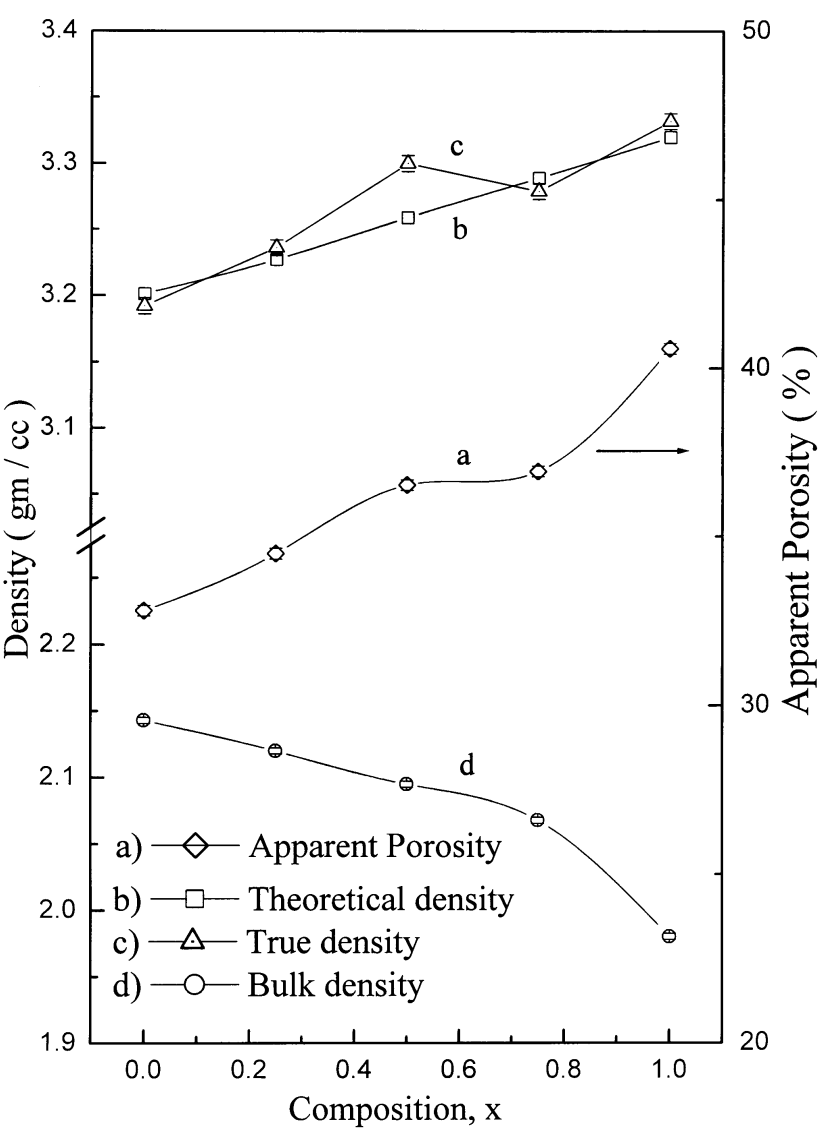

Figure 1. Density and porosity values for different compositions, $x$.

\subsection{Density}

The bulk density, true density and the apparent porosity values for the different compositions are compared with the theoretical densities in figure 1. The values of true density are found to increase with $x$ and match well with the theoretical values. With increasing $x$, while bulk density decreases, the apparent porosity increases. Thus, 
the difference between the true density and the bulk density is due mainly to the open porosity and the contribution of the closed porosity is minimum.

\subsection{Microstructure}

The SEM photographs of fracture surfaces for samples with $x=0$ and 0.50 are given in figure 2 . The average grain size of sintered specimen in this study was $2.47 \mu \mathrm{m}$ for all the compositions. This is larger than the critical grain size of $2 \mu \mathrm{m}$ for $x=0$ and smaller than that of more than $50 \mu \mathrm{m}$ for $x=1$ estimated by Yamai and Ota (1993). Thus we may expect that our samples with $x=0$ having average grain size greater than the critical grain size may show effects of micro cracking. We will soon see that our thermal expansion results reflect this.

\subsection{Thermal expansion coefficient}

The $\Delta L / L$ vs temperature plots obtained during the heating and cooling cycles for the five compositions are

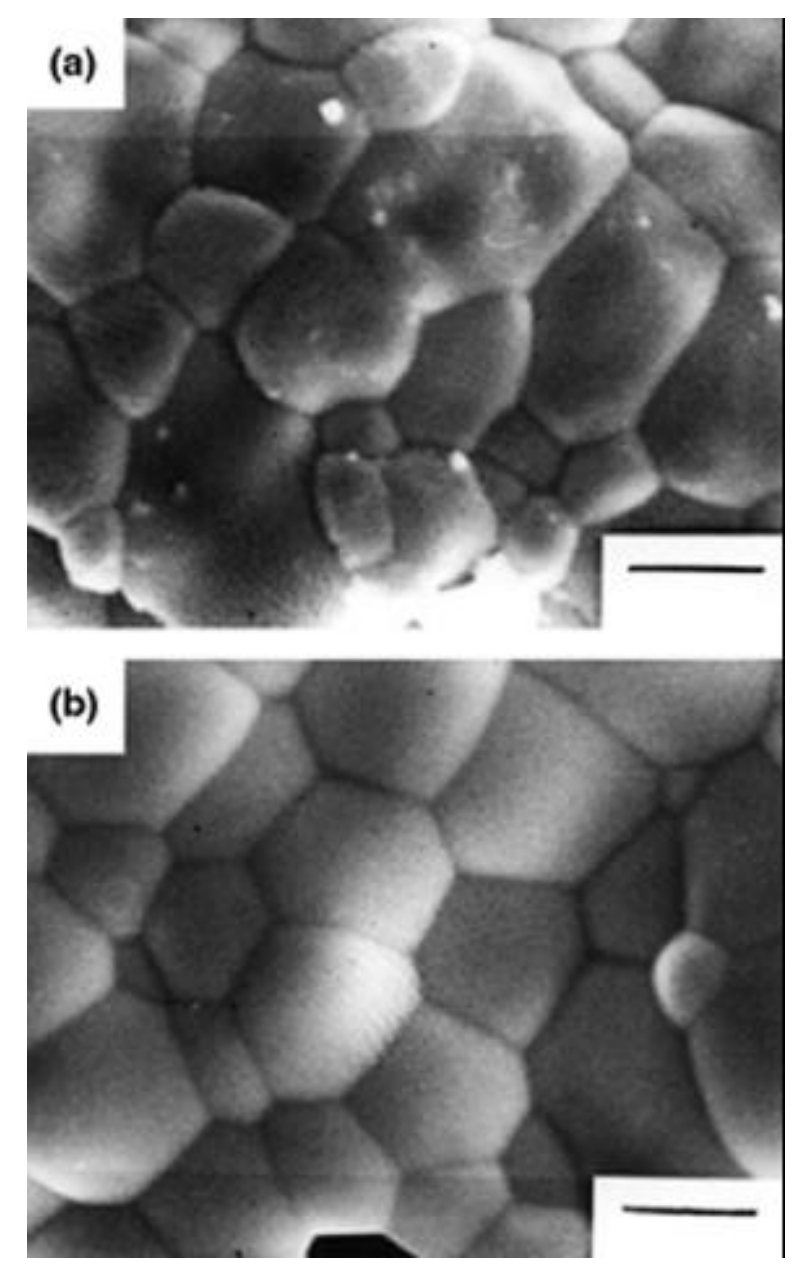

Figure 2. SEM photographs for two compositions of $x$ : (a) 0 and $(\mathbf{b}) 0.50(\mathrm{Bar}=2 \mu \mathrm{m})$. shown in figure 3. The $x=0$ composition shows contraction during heating followed by further contraction during cooling cycle. All the other compositions ( $x=$ $0.25,0.50,0.75$ and 1 ) show expansion during heating and contraction during cooling. From these plots the average value of thermal expansion coefficient, $\alpha$, over the temperature range $25-800^{\circ} \mathrm{C}$ are obtained and are shown in column 4 of table 1 . We see that the $x=0.25$ composition shows minimum expansion and that the value of $\alpha$ increases with $x$. We may now compare our values of $\alpha$ with those reported by others. In literature, Limaye et al (1991) have reported $\alpha$ for CSZP and for compositions similar to ours but over a shorter temperature range $25-500^{\circ} \mathrm{C}$. Hence, to compare our values with their values we have obtained again the $\alpha$ values over this temperature range from the plots in figure 3 . The two sets of values are shown in columns 5 and 6 , respectively of table 1 . We see that variations of $\alpha$ with $x$ show similar trend in the two sets but the numerical values differ.

It would be of interest to compare our measured $\alpha$ with the value that can be obtained using the high temperature cell volume data. For $x=0,0.50$ and 1 compositions, using the $\alpha_{a}$ and $\alpha_{c}$ data of Limaye et al (1991) over the

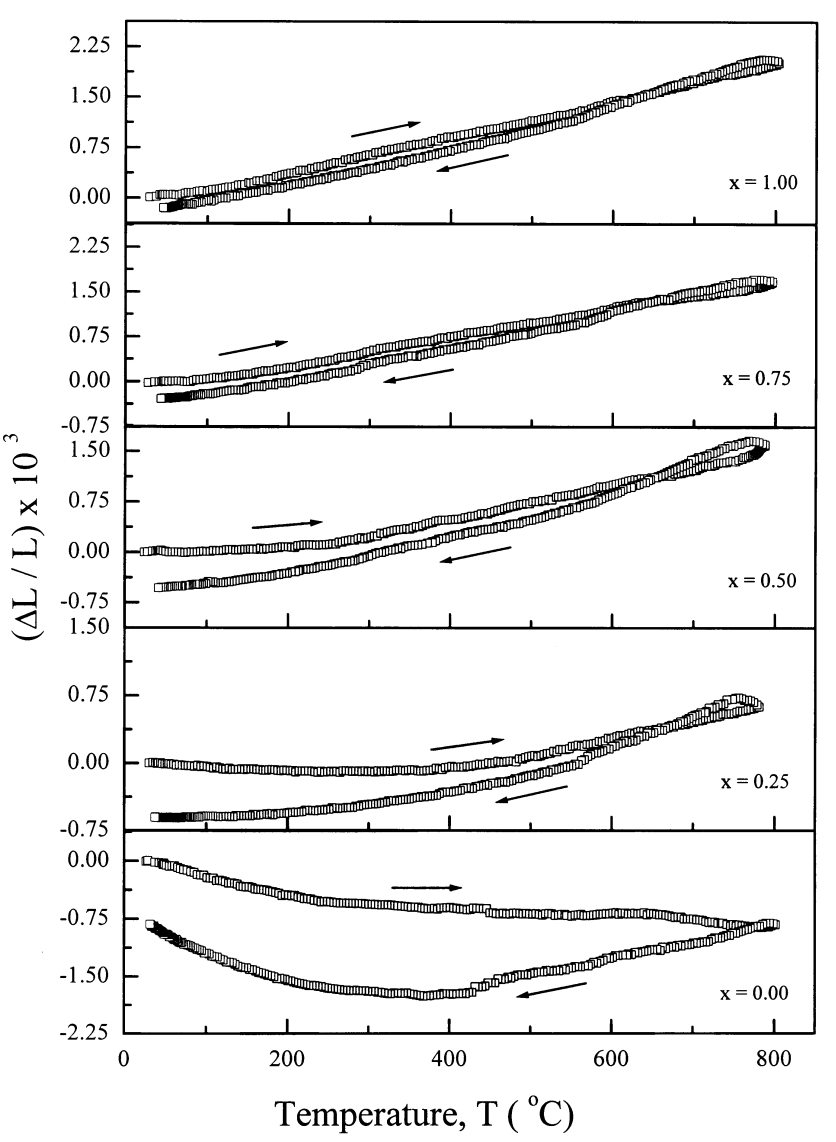

Figure 3. Dilatometric thermal expansion plots for different compositions of $x$. 
temperature range $25-500^{\circ} \mathrm{C}$ and our values for cell parameters at $25^{\circ} \mathrm{C}$ we have calculated corresponding average volume expansion coefficient $\alpha_{\mathrm{v}}$ and then obtained $\alpha_{1}=\alpha_{v} / 3$ over this range. Similarly, using the data over the temperature range $25-800^{\circ} \mathrm{C}$ reported by Huang (1990) for the two end compositions ( $x=0$ and 1) we have obtained $\alpha_{1}=\alpha_{\mathrm{v}} / 3$. These are shown respectively in columns 7 and 8 of table 1 . Thus table 1 shows the available values of $\alpha$ obtained from dilatometry and from the high temperature XRD. It is evident that there is a considerable disagreement. For $x=0$ while Huang (1990) data predicts a positive $\alpha$, our samples show high negative value; on the other hand the negative value from Limaye et al (1991) data is numerically much smaller. For $x=0.50$ the high temperature data of Limaye et al (1991) gives a small negative value but the dilatometric measurements yield a high positive value. Finally for $x=1$ our value is higher than both but nearer to that of Huang (1990). We may attribute the negative value of $\alpha$ for $x=0$ of our sample and as well as that of Limaye et al (1991) to the extensive micro cracks pre-existing in the material. Repeated thermal cycling of such a ceramic will eventually lead to a mechanically weak body.

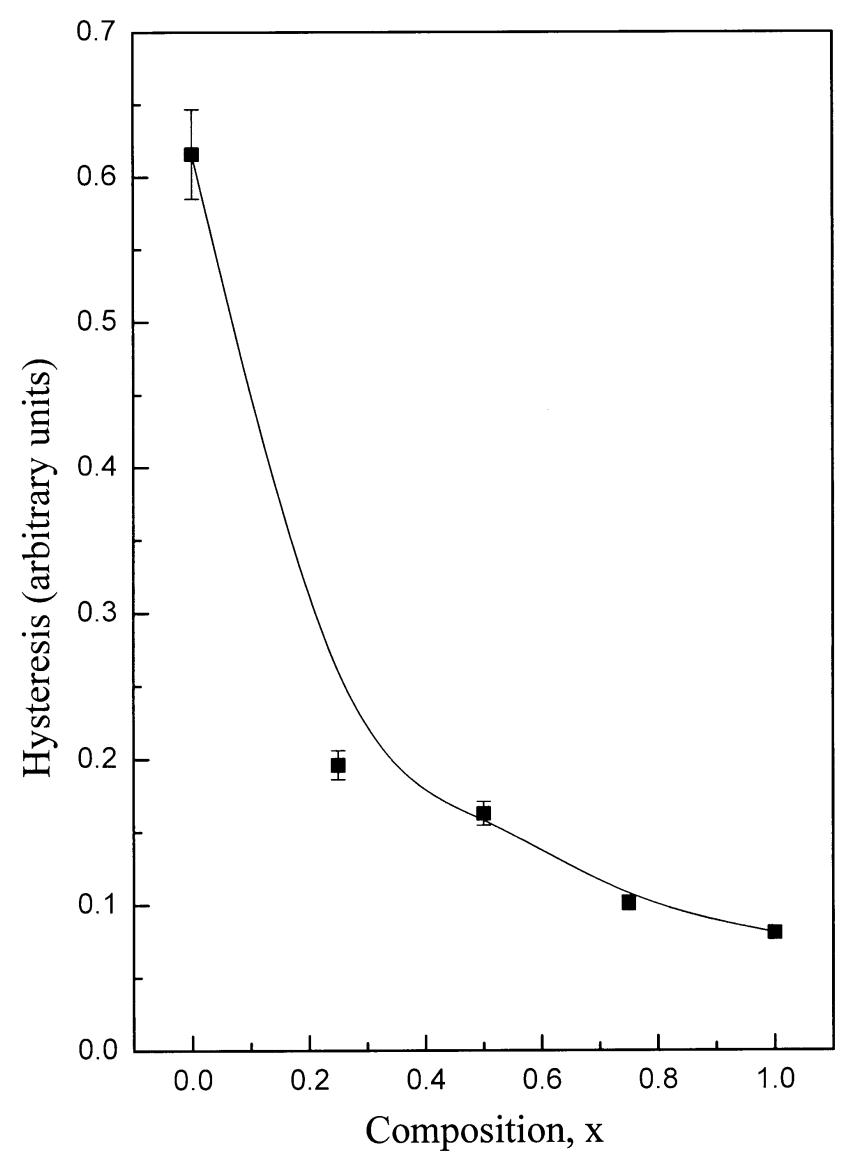

Figure 4. Variation of area under hysteresis curve with composition, $x$.

\subsection{Thermal expansion anisotropy and hysteresis}

The thermal expansion plots during the heating and cooling cycles for CSZP samples represented in figure 3 show different amounts of hysteresis for different compositions. The area under these hysteresis curves as a function of the composition is shown in figure 4 . We see that the hysteresis is maximum for $x=0$ composition and decreases progressively with increasing $x$. Yamai and Ota (1993) also observed similar hysteresis behaviour for CZP material when the average grain size was greater than $2 \mu \mathrm{m}$. The progressive decrease in the hysteresis with $x$ denotes the corresponding increase in the value of critical grain size. It is known that $\mathrm{Sr}$ substitution generally decreases the anisotropy leading to substantial increase in the critical grain size. Hence a CSZP system with composition $x \neq 0$ and heat treated as above can have the grain size below the respective critical limit. To understand the association between the hysteresis and the thermal expansion anisotropy, the $\Delta \alpha$ values reported by Limaye et al (1991) and by Yamai and Ota (1993) for CSZP system are shown in table 2 . We notice that $\Delta \alpha$ is high for $x=0$ and low for $x=1$ and therefore it is expected that $x=0$ should show large hysteresis and the $x=1$ should show little hysteresis. Our results of figure 4 bear out this expectation.

It is worth noting the correlation between the density data and the thermal expansion hysteresis data. The tendency of decrease in hysteresis with $x$ can also be related to the progressive increase in the amount of porosity, which can take the strain developed by the thermal expansion anisotropy and can block the propagation of micro cracks. Therefore CZP ( $x=0$ composition) which is having high bulk density, high thermal expansion anisotropy and grain size larger than the critical limit shows more effects of micro cracks and, hence, exhibits large hysteresis in the bulk thermal expansion. The SZP ( $x=1$ composition), which is having low bulk density, low thermal expansion anisotropy and grain size smaller than the critical limit shows less micro cracks and hence least hysteresis. Thus, we see that the $\mathrm{Sr}$ substitution reduces bulk density, increases $\alpha$ and the critical grain size for micro cracking to occur with the consequent reduction in thermal expansion hysteresis.

Table 2. Literature values of thermal expansion anisotropy, $\Delta \alpha$, and critical grain size for different compositions, $x$.

\begin{tabular}{lccc}
\hline & \multicolumn{2}{c}{$\Delta \alpha \times 10^{6}\left({ }^{\circ} \mathrm{C}^{-1}\right)$} & \\
\cline { 2 - 4 } $\begin{array}{l}\text { Compo- } \\
\text { sition } \\
(x)\end{array}$ & $\begin{array}{c}\text { Limaye } \text { et al } \\
(1991)(\text { over } \\
\left.25-500^{\circ} \mathrm{C}\right)\end{array}$ & $\begin{array}{c}\text { Yamai and Ota } \\
(1993)(\text { over }\end{array}$ & $\begin{array}{c}\text { Critical grain size } \\
(\text { Yamai and Ota } \\
\left.1990^{\circ} \mathrm{C}\right)\end{array}$ \\
\hline 0 & 15.0 & $19 \cdot 1$ & $2.0 \mu \mathrm{m}$ \\
$0 \cdot 50$ & 1.80 & - & - \\
1 & 4.80 & 0.9 & $>50 \mu \mathrm{m}$ \\
\hline
\end{tabular}




\section{Conclusions}

We have shown that both sinter density and thermal expansion behaviour are functions of chemical composition in the system CSZP. The bulk density decreases with increase in $\mathrm{Sr}$ content. Thermal expansion coefficients are obtained over wider temperature range. The correlation between the composition, critical grain size for micro cracking to occur, thermal expansion anisotropy and the thermal expansion hysteresis have been demonstrated.

\section{Acknowledgement}

This work was supported by the Nuclear Science Centre (New Delhi) under the project No. UFUP-2303.

\section{References}

Agrawal D K and Stubican V S 1985 Mater. Res. Bull. 2099 Alamo J and Roy R 1984 J. Am. Ceram. Soc. 67 C78

Alamo J and Roy R 1986 J. Mater. Sci. 21444

Cleaveland J J and Bradt R C 1978 J. Am. Ceram. Soc. 61478

Goodenough J B, Hong H Y-P and Kofalas J A 1976 Mater. Res. Bull. 11203
Harshe G, Agrawal D K and Limaye S Y 1994 J. Am. Ceram. Soc. 771965

Hong H Y-P 1976 Mater. Res. Bull. 11173

Huang C-Y 1990 Thermal expansion behaviour of sodium zirconium phosphate structure type materials, $\mathrm{Ph} . \mathrm{D}$. thesis, Pennsylvania State University, Pennsylvania

Lenain G E, McKinstry H A, Limaye S Y and Woodward A 1984 Mater. Res. Bull. 191451

Lenain G E, McKinstry H A, Alamo J and Agrawal D K 1987 J. Mater. Sci. 2217

Limaye S Y, Agrawal D K and McKinstry H A 1987 J. Am. Ceram. Soc. $\mathbf{7 0} \mathrm{C} 232$

Limaye S Y, Agrawal D K, Roy R and Mehrotra Y 1991 J. Mater. Sci. 2693

Mendelson M I 1969 J. Am. Ceram. Soc. 52443

Oota T and Yamai 1986 J. Am. Ceram. Soc. 691

Roy R, Agrawal D K, Alamo J and Roy R A 1984 Mater. Res. Bull. 19471

Srikanth V, Subbarao E C, Agrawal D K, Huang C-Y, Roy R and Rao G V 1991 J. Am. Ceram. Soc. 74365

Umarji A M, Senbhagaraman S and Radhika Rao M V 1997 J. Instr. Soc. India 27109

Wurst J C and Nelson J A 1972 J. Am. Ceram. Soc. 55 109

Yamai I and Ota T 1985 J. Am. Ceram. Soc. 68273

Yamai I and Ota T 1993 J. Am. Ceram. Soc. 76487

Yvon R, Wolfgang J and Ervin P 1977 J. Appl. Cryst. 1073 